\title{
Synthesis of molybdenum-incorporated mesoporous silicates by evaporation- induced self-assembly: Insights into surface oxide species and corresponding olefin metathesis activity
}

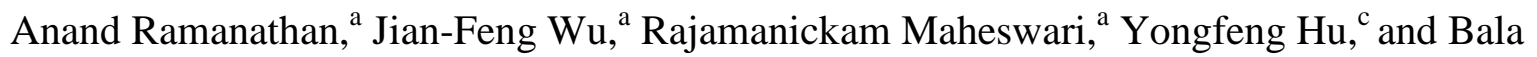
Subramaniam $^{\mathrm{a}, \mathrm{b}^{*}}$

${ }^{\mathrm{a}}$ Center for Environmentally Beneficial Catalysis, The University of Kansas, Lawrence, KS 66047, USA

${ }^{\mathrm{b}}$ Department of Chemical and Petroleum Engineering, The University of Kansas, Lawrence, KS 66045, USA

${ }^{\mathrm{c}}$ Canadian Light Source, 44 Innovation Boulevard, Saskatoon, SK, Canada

*Corresponding author. E-mail: bsubramaniam@ku.edu, Tel.: +1-785-864-2903; fax: +1-785864-6051.

\begin{abstract}
Molybdenum-incorporated mesoporous silicates with different Si/Mo ratios were synthesized via the Evaporation Induced Self-Assembly (EISA) method. SAXS and nitrogen physisorption results confirm the ordered mesoporosity. The BET surface area, pore volume and pore size distribution generally decrease with Mo loading while preserving the mesoporosity. Highly dispersed monomeric and oligomeric $\mathrm{MoO}_{\mathrm{x}}$ species $\left(\mathrm{Mo}^{6+}\right.$ oxidation state) were evident from diffuse reflectance UV-Vis and XPS spectra. $\mathrm{H}_{2}$-TPR results confirm the existence of polymeric $\mathrm{MoO}_{\mathrm{x}}$ and bulk crystalline $\mathrm{MoO}_{3}$ species. At lower loadings, Mo exits in both tetrahedral and octahedral symmetry as established by Mo L3-edge XANES studies. Mo-EISA catalysts with highly dispersed isolated $\mathrm{MoO}_{\mathrm{x}}$ sites display stable activity for 2-butene + ethylene metathesis that is comparable to those reported for $\mathrm{WO}_{3} / \mathrm{SiO}_{2}$ catalysts.
\end{abstract}

Keywords: EISA; mesoporous; molybdenum; metathesis. 


\section{Introduction}

Supported molybdenum-based catalysts have been explored for various types of reactions including olefin epoxidation [1-3], partial oxidation of methane [4-6], methanol oxidation [7, 8], ethanol oxidation [9], oxidative dehydrogenation [10-13], esterification and transesterification $[14,15]$, biomass pyrolysis [16, 17] and olefin metathesis [18-21]. Molybdenum species have been incorporated into well-known mesoporous silicates such as MCM-41, MCM-48 and SBA15 mainly via grafting or impregnation techniques [2, 22-25]. For Mo-SBA-15 materials prepared by co-condensation method at two different $\mathrm{HCl}$ concentrations $(0.5 \mathrm{~N}$ and $1.9 \mathrm{~N})$ with $\mathrm{Si} / \mathrm{Mo}$ mole ratio varying from 25 to 12.5 , the metal incorporation efficiency is less than $60 \%$ [26]. Budhi et al. studied the effect of diammonium hydrogen phosphate (DHP) as an additive during Mo-SBA-15 synthesis. They report that DHP increased the metal incorporation by 2-3 fold compared to samples prepared without DHP [27]. Nevertheless, the metal loading efficiency is still low ( $30-35 \%)$. Low levels of Mo incorporation ( $40-60 \%$ of Mo in the synthesis gel) were also reported when Mo was incorporated into KIT-6 [28] and KIT-5 [29] silicates by the hydrothermal synthesis route. This is in general attributed to the differences in the oxidation state of molybdenum $\left(\mathrm{Mo}^{6+}\right)$ compared to silicon $\left(\mathrm{Si}^{4+}\right)$ preventing isomorphic substitution.

Despite the low Mo incorporation efficiency associated with one-pot synthesis hydrothermal synthesis, a uniform dispersion of Mo species has been achieved. Higashimoto et al. prepared Mo-MCM-41 with 0.5-4wt\% Mo loading by direct hydrothermal synthesis method under acidic conditions $(\mathrm{pH}=0.5)$ and observed tetra-coordinated monomeric molybdate species at low loading (0.5 and $1 \mathrm{wt} \% \mathrm{Mo})$ and, in addition, dimeric and oligomeric molybdate species at high Mo content (2.0-4.0 wt\%) [30]. Briot et al. prepared Mo-SBA-15 and Mo-MCM-41 employing oxo-peroxo Mo species as Mo precursors by reacting $\mathrm{MoO}_{3}$ with $\mathrm{H}_{2} \mathrm{O}_{2}$ and an optimum ratio of surfactants (P123 and cetyltrimethylammonium chloride) to obtain complete incorporation of the Mo species in the synthesis mixture without disrupting the ordered structure of SBA-15 [31]. Using ammonium heptamolybdate as the Mo source, it was shown that complete incorporation of the Mo species present in the synthesis mixture into various mesoporous silicates (MCM-41, MCM-84, HMS and SBA-3) was not possible under basic conditions. Under acidic synthesis conditions $(\mathrm{pH} \sim 2)$ however, the $\mathrm{Si} / \mathrm{Mo}$ ratio in the synthesis mixture and the final synthesized materials was nearly identical implying complete metal incorporation [32]. 
In general, the use of ordered mesoporous silicates as supports tend to enhance the accessibility of the active species. We have recently shown that $\mathrm{W}$-incorporated mesoporous silicates such as W-KIT-6, W-KIT-5 and W-SBA-15 provide enhanced 1-butene+ethylene metathesis activity [33]. Further, by modifying the synthesis condition, particularly by optimally delaying the addition of the tungsten precursor, the propylene yield can be further enhanced. This is due to an enrichment in surface W species as confirmed by XPS spectra. More recently, we showed that W-EISA catalysts perform even better than the best performing W-KIT-6 catalyst [34]. Further, all the W-incorporated mesoporous catalysts showed superior metathesis performance when compared to tungsten impregnated $\mathrm{SiO}_{2}$ catalysts [33]. Another advantage of mesoporous catalysts is that the larger pore volume and pore diameter can accommodate more coke and the pore channels are not easily blocked compared to microporous catalysts. This results in lower deactivation rate and longer life time [35].

Complementing the direct hydrothermal synthesis route, a variety of mesoporous metal oxides (including silicate and non-silicate systems) have been prepared using the Evaporation Induced Self-Assembly (EISA) method [36-39]. We recently reported $\mathrm{Zr}^{4+}$ incorporation into mesoporous silica via the EISA method, obtaining $\mathrm{Zr}$ loadings as high as 15 wt.\% without evidence of bulk $\mathrm{ZrO}_{2}$ formation [40]. Similarly, W-EISA catalysts were also prepared with high accessibility of $\mathrm{W}$ species up to a tungsten loading of $13.8 \mathrm{wt} \%[34]$. In the EISA method, all the metal in the synthesis gel is expected to be retained in the final solid. Depending on the metal loading, various types of metal oxide species, including aggregated bulk $\mathrm{MO}_{\mathrm{x}}$ species, are typically observed. In this work, we report for the first time the synthesis and characterization of Mo-incorporated mesoporous silicate via the EISA method using P123 triblock copolymer as structure-directing agent and $\mathrm{MoCl}_{5}$ as molybdenum source. The resulting materials show tunable acidity and remarkable catalytic performance for the metathesis of 2-butene and ethylene to produce propene. 


\section{Experimental}

\subsection{Materials}

Tri-block co-polymer (Pluronic P123, $\mathrm{EO}_{20}-\mathrm{PO}_{70}-\mathrm{EO}_{20}$, with an average molecular weight 5,800, Aldrich), ethanol (Absolute, 200 Proof, Acros organics), tetraethyl orthosilicate (TEOS) (98\% Acros organics) and Molybdenum(V) chloride (99.6\%, Alfa Aesar) were used as received.

\subsection{Synthesis of Mo-EISA}

A series of $\mathrm{MoO}_{\mathrm{x}}-\mathrm{SiO}_{2}$ materials with different $\mathrm{Si} / \mathrm{Mo}$ ratios ranging from 10 to 100 was prepared by the EISA method, following a similar procedure reported by us for Zr-EISA materials [40]. In a typical synthesis, $4.5 \mathrm{~g}$ of P123 were dissolved in $75 \mathrm{~mL}$ of ethanol. Then, $10.0 \mathrm{~g}$ of TEOS and the required amounts of Molybdenum(V) chloride, pre-dissolved in ethanol, were added. After stirring for $2 \mathrm{~h}$, the reaction mixture was transferred to a Pyrex petri dish and left in the fume hood for nearly $48 \mathrm{~h}$. The organic contents in the resulting solid were then removed by calcination in flowing air at $550{ }^{\circ} \mathrm{C}$ for $5 \mathrm{~h}$ at a heating rate of $1.5{ }^{\circ} \mathrm{C} / \mathrm{min}$. The synthesized samples are designated as $\operatorname{Mo-EISA}(\mathrm{X})$ where $\mathrm{X}$ represents the molar Si/Mo ratio in the initial synthesis mixture. For benchmarking purpose, Mo-EISA catalysts (1.8 and $5.2 \mathrm{wt} \%$ Mo) were also prepared without the addition of P123.

\subsection{Catalyst Characterization}

Small Angle X-ray Scattering and wide angle XRD patterns of Mo-EISA samples were collected on a PANalytical Empyrean instrument in transmission and scattering modes operating at $45 \mathrm{kV}$ and $40 \mathrm{~mA}$. The elemental compositions of the samples were determined using XRF (PANalytical Zetium) instrument. Nitrogen adsorption-desorption isotherms were measured at liquid nitrogen temperature using a Quantachrome NOVA 2000e analyzer. Prior to the physisorption experiment, the samples were heated in vacuum at $200{ }^{\circ} \mathrm{C}$ for $1 \mathrm{~h}$. Diffuse reflectance UV-Vis spectra were recorded with a Perkin Elmer Lambda 850 equipped with diffuse reflectance integrating sphere, with Spectralon as the reference. The total acidity and reduction profiles were obtained from temperature programmed desorption of ammonia $\left(\mathrm{NH}_{3}\right.$ TPD) and temperature programmed reduction using hydrogen $\left(\mathrm{H}_{2}-\mathrm{TPR}\right)$ respectively, using a 
Micromeritics Autochem 2910 instrument equipped with a Thermal Conductivity Detector (TCD) as reported elsewhere [41, 42].

The X-ray photoelectron spectroscopy (XPS) measurements were carried out using a PHI 5000 versa probe II spectrometer using monochromatic $\mathrm{Al} \mathrm{K \alpha}$ radiation at an operating power of $25 \mathrm{~W}(15 \mathrm{kV})$ and focused to a diameter of $100 \mu \mathrm{m}$. The electron takeoff angle was $45^{\circ}$ with respect to the sample surface and the core-level spectra were acquired at a pass energy of 23.5 $\mathrm{eV}$ with $0.2 \mathrm{eV}$ energy step. The binding energies were corrected with reference to $\mathrm{SiO}_{2}$ at 103.6 $\mathrm{eV}$. The Mo3d experimental curve was fitted using CasaXPS software to a Gaussian-Lorentzian peak shape with spin orbital pair intervals set at $3.15 \mathrm{eV}$ and a spin-orbit area ratio of 1.5.

X-ray absorption near edge structure (XANES) spectroscopy was used to understand the coordination structure of molybdenum. Mo $\mathrm{L}_{3}$-edge spectrum was collected at the SXRMB Beamline of Canadian Light Source. A Si(111) double crystal monochromator was used to cover the Mo $\mathrm{L}_{3}$-edge by setting the edge energy of Mo $\mathrm{L}_{3}$-edge to $2520 \mathrm{eV}$. The incoming beam was monitored by the $\mathrm{I}_{0}$ recorded from the ion chamber located upstream of the sample. Fluorescence spectrum was recorded using a 4-element $\mathrm{Si}(\mathrm{Li})$ drift detector. The XANES data were processed using Athena.

\subsection{Metathesis activity testing}

About $1 \mathrm{~g}$ of catalyst with particle sizes ranging from $0.250-0.425 \mathrm{~mm}$ in diameter was placed at the center of a fixed bed reactor and activated in situ with $\mathrm{N}_{2}$ at $550^{\circ} \mathrm{C}$. Then a mixture of ethylene and 2-butene with a molar ratio of 3 was fed to the reactor $\left(\mathrm{T}=450{ }^{\circ} \mathrm{C}, \mathrm{P}=1 \mathrm{~atm}\right)$ at a weight hourly space velocity (WHSV) of $2.0 \mathrm{~h}^{-1}$. The products were analyzed by an online Varian CP-3800 gas chromatograph equipped with an Agilent GS-gaspro ${ }^{\circledR}$ column $(30 \mathrm{~m} \times 0.320 \mathrm{~mm})$ and a flame ionization detector (FID). Details of the experimental are described elsewhere [33]. The definitions of 2-butene conversion, propene selectivity, propene yield and apparent turnover frequency (TOF) are as follows:

$$
\begin{aligned}
& X_{2-\text { butene }}=\frac{[2-\text { butene }]_{\text {in }}-[2-\text { butene }]_{\text {out }}}{[2-\text { butene }]_{\text {in }}} \times 100 \\
& S_{\text {propene }}=\frac{[\text { propene }]_{\text {out }}}{[2-\text { butene }]_{\text {in }}-[2-\text { butene }]_{\text {out }}} \times 100 \%
\end{aligned}
$$




$$
\begin{gathered}
Y_{\text {propene }}=X_{2-\text { butene }} \times S_{\text {propene }} \times 100 \% \\
\operatorname{TOF}\left(s^{-1}\right)=\frac{W H S V_{2-\text { butene }}\left(g \cdot h^{-1}\right) / M_{2-\text { butene }}\left(g \cdot \mathrm{mol}^{-1}\right) \times Y_{\text {propene }}}{3600\left(s \cdot h^{-1}\right)} / \frac{m_{\text {catalyst }}(g) \times W w t \%}{M_{W}\left(g \cdot \mathrm{mol}^{-1}\right)}
\end{gathered}
$$

Even though the measured conversions are free from external mass transfer limitations, the term "apparent" is used to qualify the estimated turnover frequencies to reflect the fact that not all the accessible Mo metal may be active for metathesis. In this manner, it is possible to obtain comparative information on the active Mo species that are accessible at various Mo loadings.

\section{Results and discussion}

The SAXS patterns of Mo-EISA samples (Figure 1) display one broad peak at very low angle $\left(2 \theta=1.12-1.17^{\circ}\right)$ similar to the (100) peak observed for SBA-15 [43]. Since no additional characteristic SBA-15 peaks were observed for the Mo-EISA samples, the mesoporous structure in these samples is inferred to be of short range order. Further, the intensity of this main peak decreased with Mo loading and no peak was observed for the Mo-EISA(10) sample, corresponding to $18.5 \mathrm{wt} \%$ Mo. Nevertheless, all these samples exhibit a Type IV adsorption isotherm characteristic of mesoporous materials and a H1-type hysteresis loop indicative of narrow distribution of uniform channel-like pores with exception of Mo-EISA(20) which showed hysteresis similar to MCM-41 type materials (Figure 2). The BET specific surface area and total pore volume decreased from 517 to $109 \mathrm{~m}^{2} / \mathrm{g}$ and from 0.53 to $0.17 \mathrm{~cm}^{3} / \mathrm{g}$ respectively with an increase in Mo content from 2 to $20 \mathrm{wt}$ \% (Table 1). While the measured pore diameter of the Mo-EISA samples decreased from 4.3 to $2.8 \mathrm{~nm}$ as the Mo loading increased from 1.84 to 10.8 wt. $\%$, it increased to $10.6 \mathrm{~nm}$ at $18.5 \mathrm{wt} . \%$ Mo, suggesting that progressively greater heteroatom incorporation has a significant influence on the formation of the mesophase.

Typically, a narrow pore size distribution that varies less (10-20\% change) with metal loading can be achieved under acidic synthesis conditions when using non-ionic surfactants such as P123. This trend is observed during Zr-EISA synthesis where the presence of water results in such a pore size distribution [40]. However, due to the exothermic reaction of $\mathrm{MoCl}_{5}$ with water, we avoided using water during Mo-EISA synthesis. This may influence the more significant variations (more than twofold) in mean pore size with Mo loading. Further, at the highest Mo loading (18.5 wt\%), the pore size distribution and mean pore size may be influenced by the extraframework Mo oxides that also form. 
TEM images of the Mo-EISA samples show the formation of uniform mesopores, consistent with the nitrogen physisorption (Figure 3A and Figure 4, top row). STEM and elemental mapping of Mo-EISA (100 and 40) samples showed uniform dispersion of Mo species (Figure 4). Interestingly, bigger particles are clearly evident at the higher Mo loadings (Figure 3C, Figure 3D and Figure 4, bottom row).

High-angle XRD patterns of Mo-EISA samples show a broad peak centered around $2 \theta=22^{\circ}$ attributed to amorphous silica (Figure 5). No diffraction lines characteristic of $\mathrm{MoO}_{\mathrm{x}}$ species could be detected in samples with Mo loading up to $10.8 \mathrm{wt} . \%$ indicating the formation of highly dispersed $\mathrm{MoO}_{\mathrm{x}}$ species (isolated molybdate or polymolybdate) either within the framework or on the surface of the mesoporous silicate. However, characteristic $\mathrm{MoO}_{3}$ reflections $\left(\mathrm{MoO}_{3}\right.$ ICDD:98-015-2315) with relatively lower intensity were clearly evident for the 18.5 wt.\% Mo sample indicating the formation of some $\mathrm{MoO}_{3}$ species as well at higher Mo loadings [21].

The $\mathrm{H}_{2}$-TPR profiles (Figure 6) show one broad reduction profile centered at $838{ }^{\circ} \mathrm{C}$ for the Mo-EISA (100) sample containing 1.84 wt.\% Mo. Such high temperature reduction peak is usually attributed to the presence of highly dispersed monomeric $\mathrm{MoO}_{x}$ species with strong interactions with the mesoporous silica surface [12, 24, 44, 45]. A similar but broader profile was observed for the Mo-EISA(40), sample containing $5.2 \mathrm{wt} \% \mathrm{Mo}$, but at a lower temperature centered at $730{ }^{\circ} \mathrm{C}$ indicating the presence of oligomeric $\mathrm{MoO}_{x}$ species as well. At higher Mo loadings, reduction at lower temperatures may occur due to local temperature increases caused by the exothermic nature of the reduction reaction. The distinct low and high temperature peaks at higher Mo loadings (10.8 and $18.5 \% \mathrm{Mo}$ ) are attributed to step wise reduction of $\mathrm{MoO}_{3}$ crystallites: $\mathrm{Mo}(\mathrm{VI}) \rightarrow \mathrm{Mo}(\mathrm{IV}) \rightarrow \operatorname{Mo}(0)$ [45].

The diffuse reflectance UV-Vis spectra of Mo-EISA samples carried out under ambient conditions showed a shoulder between 215 and $240 \mathrm{~nm}$ and a clear peak around 300-320 nm (Figure 7). In general, the absorption band located in the region between $200-250 \mathrm{~nm}$ is commonly attributed to isolated molybdate species $(\mathrm{Mo}=\mathrm{O})$ in a tetrahedral coordination environment while the band at $300-320 \mathrm{~nm}$ is assigned to oligomeric Mo species (Mo-O-Mo) in an octahedral environment $[12,21,24,26,46,47]$. From these profiles, it is concluded that predominantly oligomerized octahedral molybdenum species exists in Mo-EISA samples at all the Mo loadings. An increase in the cluster size of the Mo species is also evident from the 
progressive red-shift of these peaks with Mo loading. Further, the subtle shoulder band around $400 \mathrm{~nm}$ observed with the Mo-EISA(10) sample with $18.5 \mathrm{wt} \%$ Mo suggests the presence of bulk $\mathrm{MoO}_{3}$ species on the catalyst surface consistent with wide angle XRD analysis (Figure 5).

The $\mathrm{NH}_{3}$-TPD profiles of Mo-EISA samples (Figure 8) between 100 and $550{ }^{\circ} \mathrm{C}$ show a very broad desorption peak in the $100-350{ }^{\circ} \mathrm{C}$ range (Figure 8). The amount of ammonia desorbed and hence the total acidity of Mo-EISA samples increased with Mo content. The peak maxima are centered around $170-180{ }^{\circ} \mathrm{C}$ indicating the weak nature of acid sites in these samples. Additionally, acidity of medium strength was also observed for the Mo-EISA samples with the higher Mo loadings (10.8 and 18.5 wt.\%) as evidenced from the broad tailing from $250-300{ }^{\circ} \mathrm{C}$.

Figure 9 presents the comparative catalytic activity of Mo-EISA materials with different Mo content for the metathesis of 2-butene and ethylene. Propylene was observed as the major product with 1-butene and pentenes as minor products. A typical break-in period of about 1-1.5 h [33] during which the active Mo species $\left(\mathrm{Mo}=\mathrm{CH}_{2}\right.$ or Mo-cyclobutane intermediate) are believed to form [48], was observed at all four Mo loadings. The propylene yield increases as the Mo loading is increased from 1.84 wt.\% to $5.2 \mathrm{wt} \%$ but decreases at higher Mo loadings. In addition, while the observed metathesis activity on the Mo-EISA (100) sample (1.84 wt.\% Mo) remained more or less steady throughout the 7-hour run, the 2-butene conversion and propylene yield decreased with time at the higher loadings ranging from 47-63\% and 34-54\%, respectively. Furthermore, the deactivation rate became progressively more severe at the higher Mo loadings wherein the measured acidity was higher and nanocrystalline $\mathrm{MoO}_{3}$ species with higher total acidity were detected [49]. The deactivation is attributed to the formation of cokelike deposits. For comparison, we also prepared Mo-EISA catalysts (1.8 and $5.2 \mathrm{wt} \%$ ) without adding P123 (structure directing agent). These catalysts showed very low surface area $\left(<10 \mathrm{~m}^{2} / \mathrm{g}\right)$ and thus poor dispersion of Mo species leading to negligible yield of propylene $(<2 \%)$. Clearly, the presence of P123 is necessary to generate mesoporosity and obtain better accessibility of active Mo species. As shown in Table 2, the apparent TOF (9.37 $\mathrm{mmol}_{\text {propene }} \mathrm{mol}_{\mathrm{Mo}}{ }^{-1} \mathrm{~s}^{-1}$ ), estimated from the steady propene yield observed with the Mo-EISA (100) catalyst, is significantly greater than the value reported with the W-KIT-6 (5.9 wt\% W) catalyst (5.65 $\mathrm{mmol}_{\text {propene }} \mathrm{mol}_{\mathrm{W}}^{-1} \mathrm{~s}^{-1}$ ) prepared by one pot hydrothermal synthesis method [33]. 
XPS spectra for the Mo-EISA(10) sample (Figure 10) exhibits one characteristic doublet of hexavalent molybdenum at 233.0 and $236.1 \mathrm{eV}$ attributed to Mo $3 \mathrm{~d}_{5 / 2}$ and Mo $3 \mathrm{~d}_{3 / 2}$ orbitals, respectively $[50,51]$, indicating that molybdenum exists primarily as $\mathrm{Mo}^{6+}$. In contrast, both the Mo-EISA (100) and Mo-EISA (40) samples reveal additional peaks. The binding energy at 231.4 $\mathrm{eV}$ and $234.6 \mathrm{eV}$ is attributed to Mo $3 \mathrm{~d}_{5 / 2}$ and Mo $3 \mathrm{~d}_{3 / 2}$ orbitals of $\mathrm{Mo}^{5+}$ species. These peaks are clearly not evident at the highest Mo loading (Table 3). Clearly, $\mathrm{Mo}^{5+}$ species are the more active species for olefin metathesis.

For Mo in the tetrahedral coordination, d-orbital splitting of 1.8 to $2.4 \mathrm{eV}$ was observed in Mo $\mathrm{L}_{3}$-edge XANES [52, 53]. Similarly, d-orbital splitting of 3.1 to $4.5 \mathrm{eV}$ is attributed to Mo in octahedral symmetry. Figure 11 shows the normalized and the second derivative of $\mathrm{Mo} \mathrm{L}_{3}$-edge XANES spectra of the low loading Mo-EISA (100) sample compared to reference samples, $\mathrm{MoO}_{3}$ and $\mathrm{MgMoO}_{4}$, representing octahedral and tetrahedral symmetries respectively. The energy difference due to splitting in the normal spectrum is $2.17 \mathrm{eV}$ and in the second derivative spectrum is $2.91 \mathrm{eV}$. In comparison to the established Mo coordination of reference compounds $[52,53]$, it is concluded that Mo coexists in both tetrahedral and octahedral environments in this sample, tending more towards an octahedral symmetry.

\section{Conclusions}

Highly dispersed $\mathrm{MoO}_{\mathrm{x}}$ species (up to Mo loading of $10.8 \mathrm{wt} \%$ ) were successfully incorporated into mesoporous silicates by the EISA method with negligible, if any, formation of bulk crystalline $\mathrm{MoO}_{3}$ species. Characterization results revealed the presence of isolated molybdate or polymolybdate species depending on the Mo loading. XPS results revealed the existence of both $\mathrm{Mo}^{6+}$ and $\mathrm{Mo}^{5+}$ species at lower Mo loadings. Excellent 2-butene+ethylene metathesis activity was observed with Mo-EISA catalysts that possess highly dispersed isolated molybdate species. The presence of increasing amounts of bulk crystalline $\mathrm{MoO}_{3}$ species in the Mo-EISA catalysts at higher Mo loadings increases the acidity and causes catalyst deactivation, presumably by coking. 


\section{Acknowledgments}

This research was supported with funding partly from National Science Foundation and

Environmental Protection Agency program Networks for Sustainable Material Synthesis and Design (NSF-EPA 1339661) and partly from NSF OIA-1539105. The authors thank Dr. Prem Thapa of the Microscopy and Analytical Imaging Laboratory, University of Kansas for TEM characterizations.

\section{References}

[1] B. Horváth, M. Hronec, I. Vávra, M. Šustek, Z. Križanová, J. Dérer and E. Dobročka, Catalysis Communications, 34 (2013) 16-21.

[2] P. Célestin Bakala, E. Briot, L. Salles and J.-M. Brégeault, Applied Catalysis A: General, 300 (2006) 91-99.

[3] M. Jia, A. Seifert and W.R. Thiel, Journal of Catalysis, 221 (2004) 319-324.

[4] M.H. Tran, H. Ohkita, T. Mizushima and N. Kakuta, Applied Catalysis A: General, 287 (2005) 129-134.

[5] Y. Lou, Q. Tang, H. Wang, B. Chia, Y. Wang and Y. Yang, Applied Catalysis A: General, 350 (2008) 118-125.

[6] A.E.-A.A. Said, M.M.M.A. El-Wahab and A.M. Alian, Catalysis Letters, 146 (2015) 82-90.

[7] M. Seman, J.N. Kondo, K. Domen, R. Radhakrishnan and S.T. Oyama, The Journal of Physical Chemistry B, 106 (2002) 12965-12977.

[8] M. Banares, H.C. Hu and I.E. Wachs, Journal of Catalysis, 150 (1994) 407-420.

[9] W. Zhang, A. Desikan and S.T. Oyama, The Journal of Physical Chemistry, 99 (1995) 14468-14476.

[10] K. Chen, A.T. Bell and E. Iglesia, The Journal of Physical Chemistry B, 104 (2000) 12921299.

[11] D.L. Stern and R.K. Grasselli, Journal of Catalysis, 167 (1997) 550-559.

[12] L. Kong, J. Li, Z. Zhao, Q. Liu, Q. Sun, J. Liu and Y. Wei, Applied Catalysis A: General, 510 (2016) 84-97.

[13] M. Setnička, Z. Tišler, D. Kubička and R. Bulánek, Topics in Catalysis, 58 (2015) 866-876.

[14] A. Bail, V.C. dos Santos, M.R. de Freitas, L.P. Ramos, W.H. Schreiner, G.P. Ricci, K.J. Ciuffi and S. Nakagaki, Applied Catalysis B: Environmental, 130-131 (2013) 314-324. 
[15] X. Ma, J. Gong, S. Wang, N. Gao, D. Wang, X. Yang and F. He, Catalysis Communications, 5 (2004) 101-106.

[16] K. Murugappan, C. Mukarakate, S. Budhi, M. Shetty, M.R. Nimlos and Y. Román-Leshkov, Green Chem., 18 (2016) 5548-5557.

[17] S. Budhi, C. Mukarakate, K. Iisa, S. Pylypenko, P.N. Ciesielski, M.M. Yung, B.S. Donohoe, R. Katahira, M.R. Nimlos and B.G. Trewyn, Green Chem., 17 (2015) 3035-3046.

[18] P. Topka, H. Balcar, J. Rathouský, N. Žilková, F. Verpoort and J. Čejka, Microporous and Mesoporous Materials, 96 (2006) 44-54.

[19] D.P. Debecker, B. Schimmoeller, M. Stoyanova, C. Poleunis, P. Bertrand, U. Rodemerck and E.M. Gaigneaux, Journal of Catalysis, 277 (2011) 154-163.

[20] K. Amakawa, J. Kröhnert, S. Wrabetz, B. Frank, F. Hemmann, C. Jäger, R. Schlögl and A. Trunschke, ChemCatChem, 7 (2015) 4059-4065.

[21] C. Lin, K. Tao, H. Yu, D. Hua and S. Zhou, Catal. Sci. Technol., 4 (2014) 4010-4019.

[22] M.S. Morey, J.D. Bryan, S. Schwarz and G.D. Stucky, Chemistry of Materials, 12 (2000) 3435-3444.

[23] N. Thanabodeekij, E. Gulari and S. Wongkasemjit, Powder Technology, 173 (2007) 211216.

[24] Y. Lou, H. Wang, Q. Zhang and Y. Wang, Journal of Catalysis, 247 (2007) 245-255.

[25] G.M. Dhar, G.M. Kumaran, M. Kumar, K.S. Rawat, L.D. Sharma, B.D. Raju and K.S.R. Rao, Catalysis Today, 99 (2005) 309-314.

[26] J.A. Melero, J. Iglesias, J.M. Arsuaga, J. Sainz-Pardo, P. de Frutos and S. Blazquez, Applied Catalysis A: General, 331 (2007) 84-94.

[27] S. Budhi, C. Peeraphatdit, S. Pylypenko, V.H.T. Nguyen, E.A. Smith and B.G. Trewyn, Applied Catalysis A: General, 475 (2014) 469-476.

[28] Q. Liu, J. Li, Z. Zhao, M. Gao, L. Kong, J. Liu and Y. Wei, Journal of Catalysis, 344 (2016) 38-52.

[29] K. Tao, Q. Ma, N. Tsubaki, S. Zhou and L. Han, Journal of Molecular Catalysis A: Chemical, 416 (2016) 39-46.

[30] S. Higashimoto, Y. Hu, R. Tsumura, K. Iino, M. Matsuoka, H. Yamashita, Y. Shul, M. Che and M. Anpo, Journal of Catalysis, 235 (2005) 272-278.

[31] E. Briot, J.-Y. Piquemal and J.-M. Brégeault, New J. Chem., 26 (2002) 1443-1447. 
[32] S. Che, Y. Sakamoto, H. Yoshitake, O. Terasaki and T. Tatsumi, The Journal of Physical Chemistry B, 105 (2001) 10565-10572.

[33] J.-F. Wu, A. Ramanathan, W.K. Snavely, H. Zhu, A. Rokicki and B. Subramaniam, Applied Catalysis A: General, 528 (2016) 142-149.

[34] J.-F. Wu, A. Ramanathan and B. Subramaniam, Journal of Catalysis, in press (2017).

[35] P.A. Alaba, Y.M. Sani, I.Y. Mohammed and W.M.A. Wan Daud, Reviews in Chemical Engineering, 32 (2016).

[36] M.A. Carreon and V.V. Guliants, Chapter 16 - Mesostructuring of Metal Oxides Through EISA: Fundamentals and Applications, Ordered Porous Solids, Elsevier, Amsterdam, 2009, pp. 413-439.

[37] G.J.d.A.A. Soler-Illia, A. Louis and C. Sanchez, Chemistry of Materials, 14 (2002) 750-759.

[38] H.I. Okur, Y. Türker and O.m. Dag, Langmuir, 26 (2010) 538-544.

[39] S. Biswas, K. Mullick, S.-Y. Chen, D.A. Kriz, M.D. Shakil, C.-H. Kuo, A.M. AngelesBoza, A.R. Rossi and S.L. Suib, ACS Catalysis, 6 (2016) 5069-5080.

[40] H. Zhu, R. Maheswari, A. Ramanathan and B. Subramaniam, Microporous and Mesoporous Materials, 223 (2016) 46-52.

[41] A. Ramanathan, R. Maheswari, B.P. Grady, D.S. Moore, D.H. Barich and B. Subramaniam, Microporous and Mesoporous Materials, 175 (2013) 43-49.

[42] A. Ramanathan, R. Maheswari, D.H. Barich and B. Subramaniam, Microporous and Mesoporous Materials, 190 (2014) 240-247.

[43] D. Zhao, J. Feng, Q. Huo, N. Melosh, G.H. Fredrickson, B.F. Chmelka and G.D. Stucky, science, 279 (1998) 548-552.

[44] A. Wojtaszek-Gurdak, M. Trejda, D. Kryszak and M. Ziolek, Microporous and Mesoporous Materials, 197 (2014) 185-193.

[45] F. Arena, N. Giordano and A. Parmaliana, Journal of Catalysis, 167 (1997) 66-76.

[46] J. Li, J. Liu, L. Ren, Q. Liu, Z. Zhao, Y. Chen, P. Zhu, Y. Wei, A. Duan and G. Jiang, Journal of Energy Chemistry, 23 (2014) 609-616.

[47] J.P. Thielemann, T. Ressler, A. Walter, G. Tzolova-Müller and C. Hess, Applied Catalysis A: General, 399 (2011) 28-34.

[48] S. Lwin and I.E. Wachs, ACS Catalysis, 4 (2014) 2505-2520. 
[49] K. Amakawa, L. Sun, C. Guo, M. Hävecker, P. Kube, I.E. Wachs, S. Lwin, A.I. Frenkel, A. Patlolla, K. Hermann, R. Schlögl and A. Trunschke, Angewandte Chemie International Edition, 52 (2013) 13553-13557.

[50] Z. Li, L. Gao and S. Zheng, Materials Letters, 57 (2003) 4605-4610.

[51] P. Chandra, D.S. Doke, S.B. Umbarkar and A.V. Biradar, J. Mater. Chem. A, 2 (2014) 19060-19066.

[52] E.J. Lede, F.G. Requejo, B. Pawelec and J.L.G. Fierro, The Journal of Physical Chemistry B, 106 (2002) 7824-7831.

[53] H. Hu, I.E. Wachs and S.R. Bare, The Journal of Physical Chemistry, 99 (1995) 1089710910. 
Table 1. Textural properties of Mo-EISA samples

\begin{tabular}{lccccc}
\hline $\begin{array}{l}\text { Mo-EISA } \\
(\mathbf{S i} / \mathbf{M o})^{\mathbf{a}}\end{array}$ & $\begin{array}{c}\mathbf{M o}^{\mathrm{b}} \\
\mathbf{w t} \%\end{array}$ & $\begin{array}{c}\boldsymbol{S}_{\mathbf{B E T}}{ }^{\mathrm{c}} \\
\mathbf{m}^{\mathbf{2}} / \mathbf{g}\end{array}$ & $\begin{array}{c}\boldsymbol{V}_{\mathbf{p}, \mathbf{B J H}}{ }^{\mathrm{d}} \\
\mathbf{c m}^{\mathbf{3}} / \mathbf{g}\end{array}$ & $\begin{array}{c}\boldsymbol{d}_{\mathbf{P}, \mathbf{B J H}}{ }^{\mathrm{e}} \\
\mathbf{n m}\end{array}$ & $\begin{array}{c}\text { Total acidity }^{\mathrm{f}} \\
\mathrm{mmol} \mathrm{NH}_{3} / \mathbf{g}\end{array}$ \\
\hline 100 & 1.84 & 517 & 0.53 & 4.3 & 0.05 \\
40 & 5.2 & 517 & 0.43 & 3.4 & 0.18 \\
20 & 10.8 & 414 & 0.29 & 2.8 & 0.40 \\
10 & 18.5 & 109 & 0.17 & 10.6 & 0.37 \\
\hline
\end{tabular}

\footnotetext{
${ }^{\mathrm{a}}$ numbers in parenthesis represent $\mathrm{Si} / \mathrm{Mo}$ ratio in synthesis gel;

${ }^{\mathrm{b}}$ Mo wt\% analyzed from XRF;

${ }^{\mathrm{c}} S_{\mathrm{BET}}=$ Specific Surface Area; ${ }^{\mathrm{d}} V_{\mathrm{P}, \mathrm{BJH}}=$ Total Pore Volume measured at $\mathrm{P} / \mathrm{P}_{\mathrm{o}}=0.99 ;{ }^{\mathrm{e}} d_{\mathrm{P}, \mathrm{BJH}}=$ BJH adsorption Pore Diameter; ${ }^{\mathrm{f}}$ Total acidity determined from $\mathrm{NH}_{3}$-TPD
} 
Table 2. Comparative propylene yield and apparent TOFs of Mo-EISA and W-KIT-6 catalysts for metathesis of 2-butene and ethylene to propene

\begin{tabular}{llcc}
\hline \multicolumn{2}{l}{ Mo-EISA } & yield of Propene & Apparent TOF \\
\hline (Si/Mo) & Mo Wt $\%$ & $(\%)$ & mmol $_{\text {propene }}$ mol $_{\text {metal }}{ }^{-1} \mathbf{s}^{-1}$ \\
\hline 100 & 1.84 & 45.4 & $9.37^{\mathrm{b}}$ \\
40 & 5.2 & 54.0 & $3.94^{\mathrm{c}}$ \\
20 & 10.8 & 49.5 & $1.74^{\mathrm{c}}$ \\
10 & 18.5 & 33.9 & $0.70^{\mathrm{c}}$ \\
W-KIT-6 & $(5.9)^{\mathrm{a}}$ & 46.1 & $5.65^{\mathrm{b}}$ \\
\hline
\end{tabular}

${ }^{\mathrm{a}}$ numbers in parenthesis represent $\mathrm{W} \mathrm{wt} \%$.

${ }^{b}$ steady state performance; ${ }^{c}$ initial performance 
Table 3. Binding energies and oxidation states of molybdenum in Mo-EISA samples

\begin{tabular}{|c|c|c|c|c|c|c|c|c|}
\hline \multicolumn{2}{|c|}{ Mo-EISA } & \multicolumn{2}{|c|}{$\mathrm{Mo}^{6+}$ B.E, eV } & \multicolumn{2}{|c|}{$\mathrm{Mo}^{5+}$ B.E, eV } & \multirow{2}{*}{$\frac{\mathrm{Mo}^{6+}}{(\%)}$} & \multirow{2}{*}{$\frac{\mathrm{Mo}^{5+}}{(\%)}$} & \multirow{2}{*}{$\frac{\text { FWHM }}{\mathrm{eV}}$} \\
\hline (Si/Mo) & Mo Wt\% & $\mathbf{3} d_{3 / 2}$ & $3 d_{5 / 2}$ & $\mathbf{3} d_{3 / 2}$ & $3 d_{5 / 2}$ & & & \\
\hline 100 & 1.84 & 236.8 & 233.6 & 234.6 & 231.4 & 50.2 & 49.8 & 2.82 \\
\hline 40 & 5.2 & 236.5 & 233.3 & 234.7 & 231.5 & 54.2 & 45.8 & 2.66 \\
\hline 10 & 18.5 & 236.3 & 233.2 & - & - & 100 & - & 1.66 \\
\hline
\end{tabular}




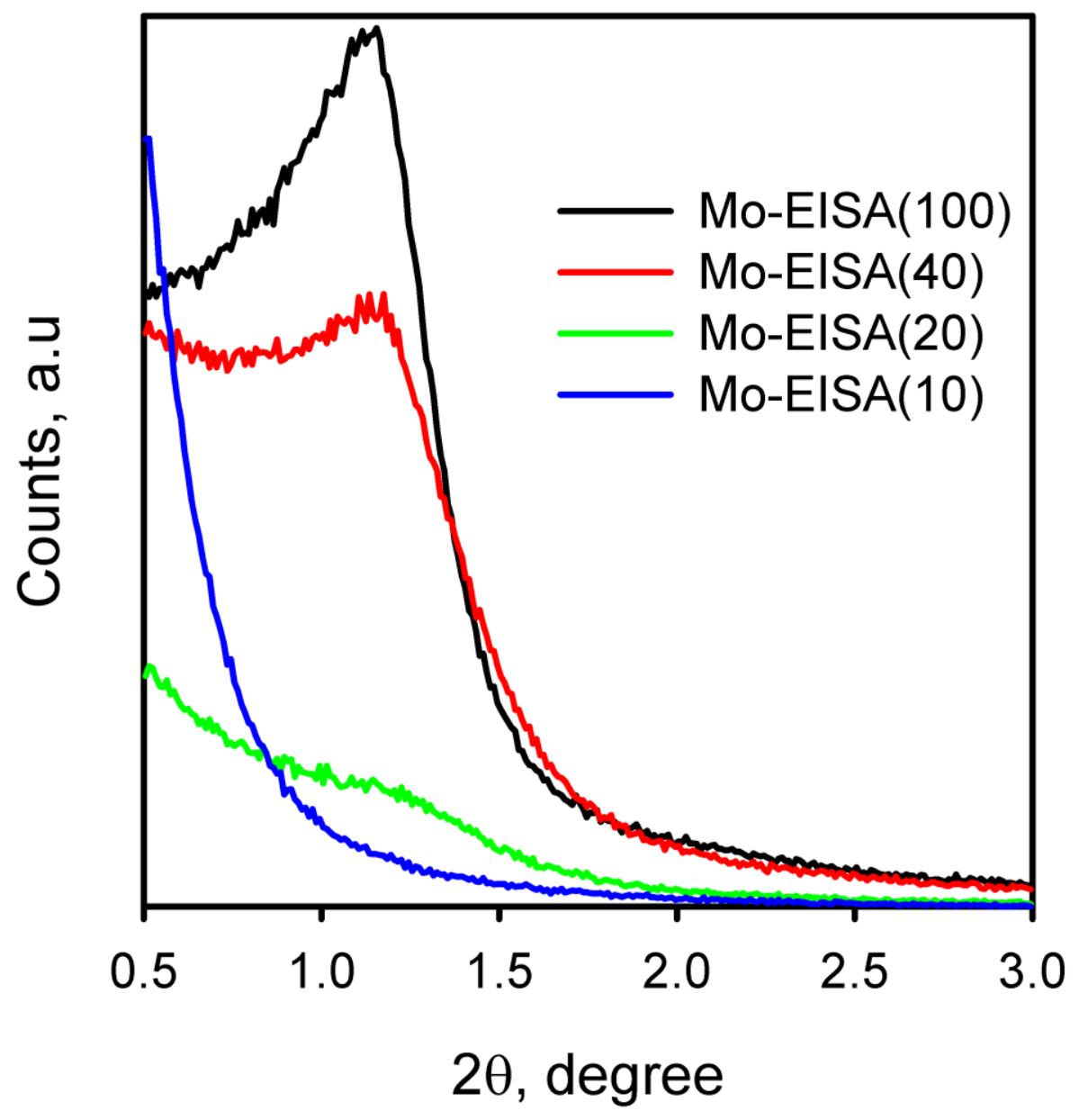

Figure 1. Small angle X-ray scattering patterns of Mo-EISA (Si/Mo) samples 

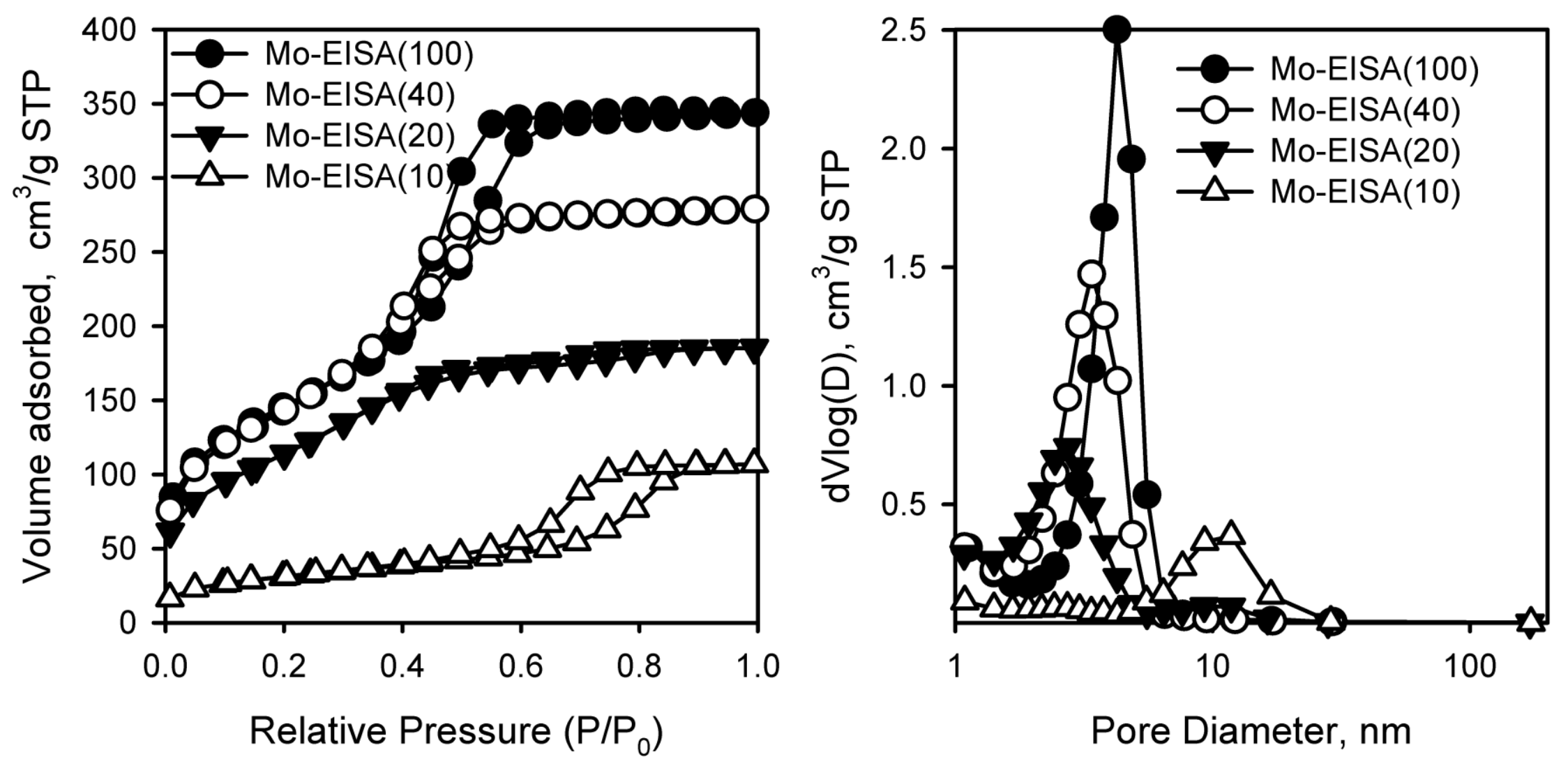

Figure 2. $\mathrm{N}_{2}$ sorption isotherms (left) and pore size distribution (right) of Mo-EISA (Si/Mo) samples 


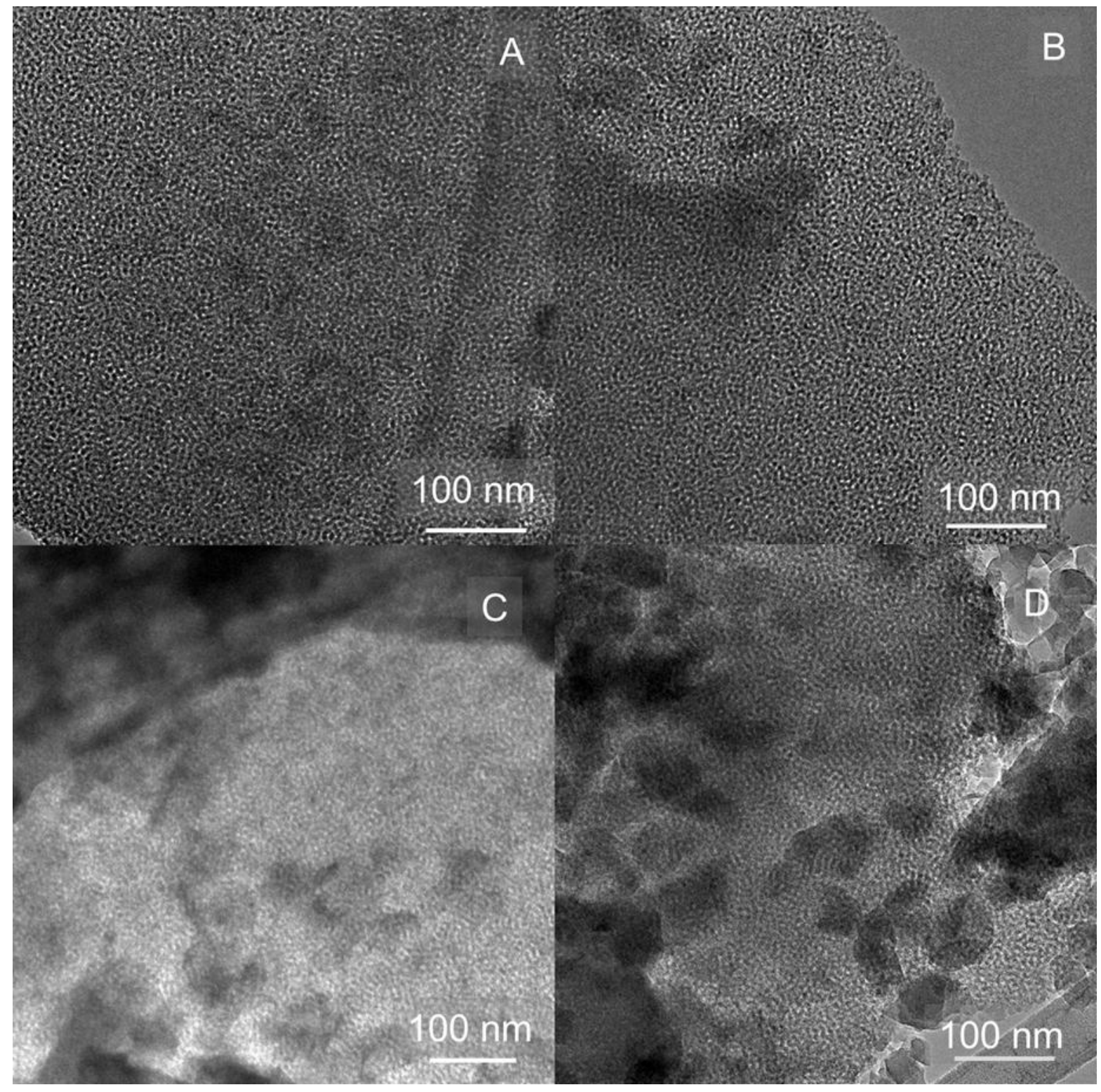

Figure 3. TEM images of Mo-EISA samples with Si/Mo ratio of (A) 100, (B) 40, (C) 20 and (D) 10. 


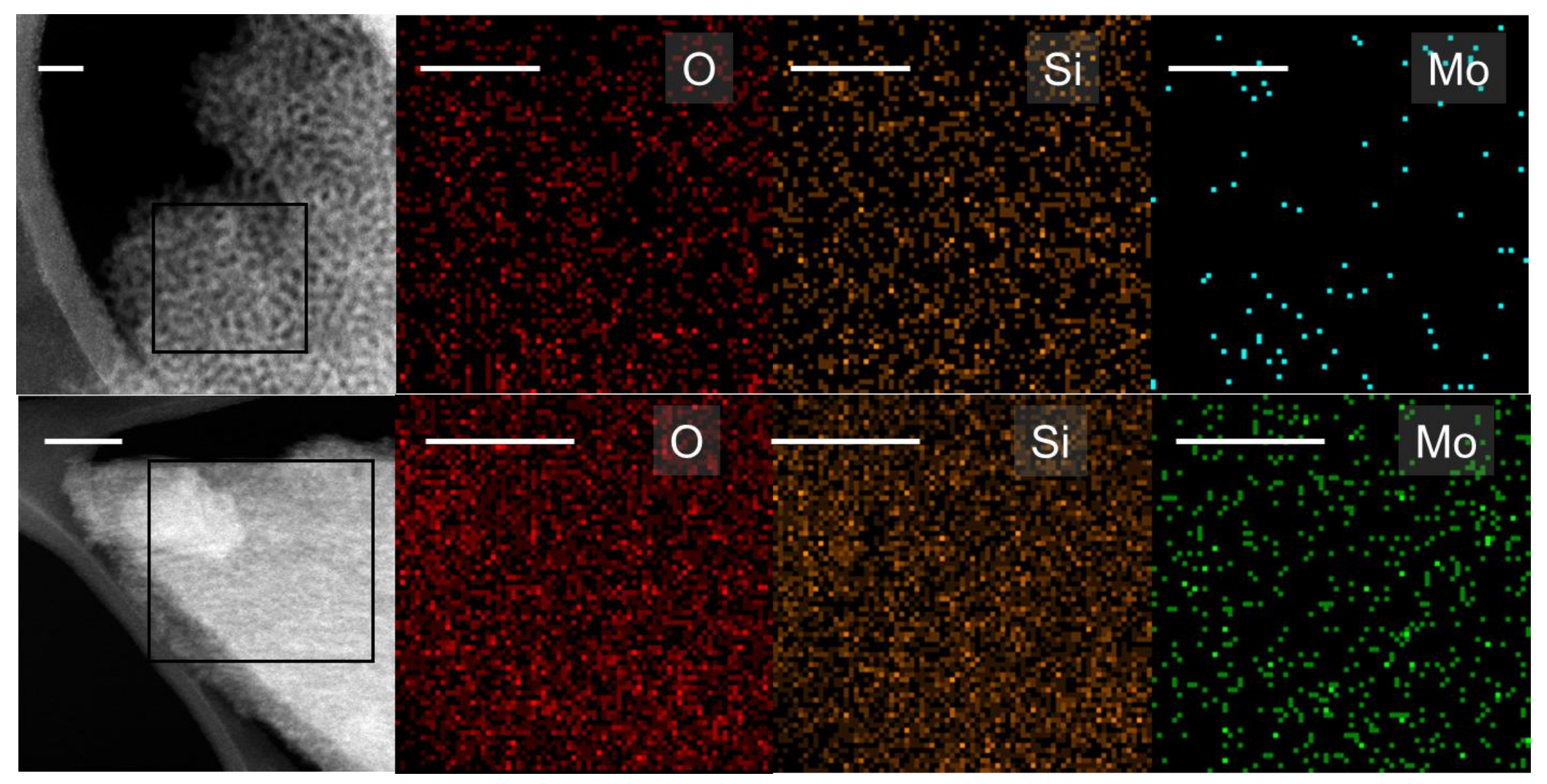

Figure 4. (Top row) STEM and elemental mapping images of Mo-EISA(100) and (Bottom row) Mo-EISA(40). The scale bar represents $20 \mathrm{~nm}$ in the top row and $100 \mathrm{~nm}$ in the bottom row 


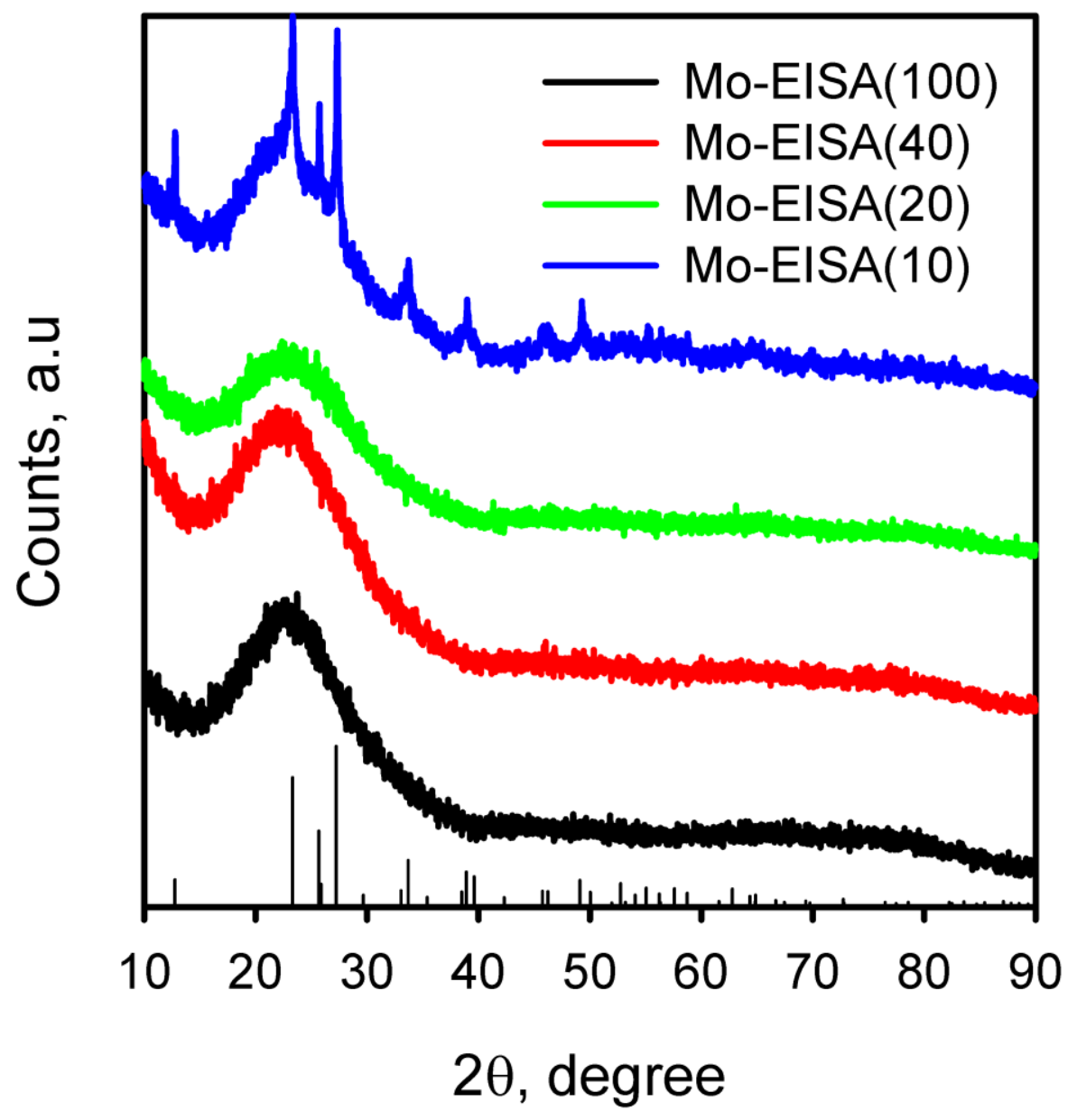

Figure 5. Wide angle XRD patterns of Mo-EISA ( $\mathrm{Si} / \mathrm{Mo}$ ) samples compared to $\mathrm{MoO}_{3}$ ICDD:98015-2315 (lines). 


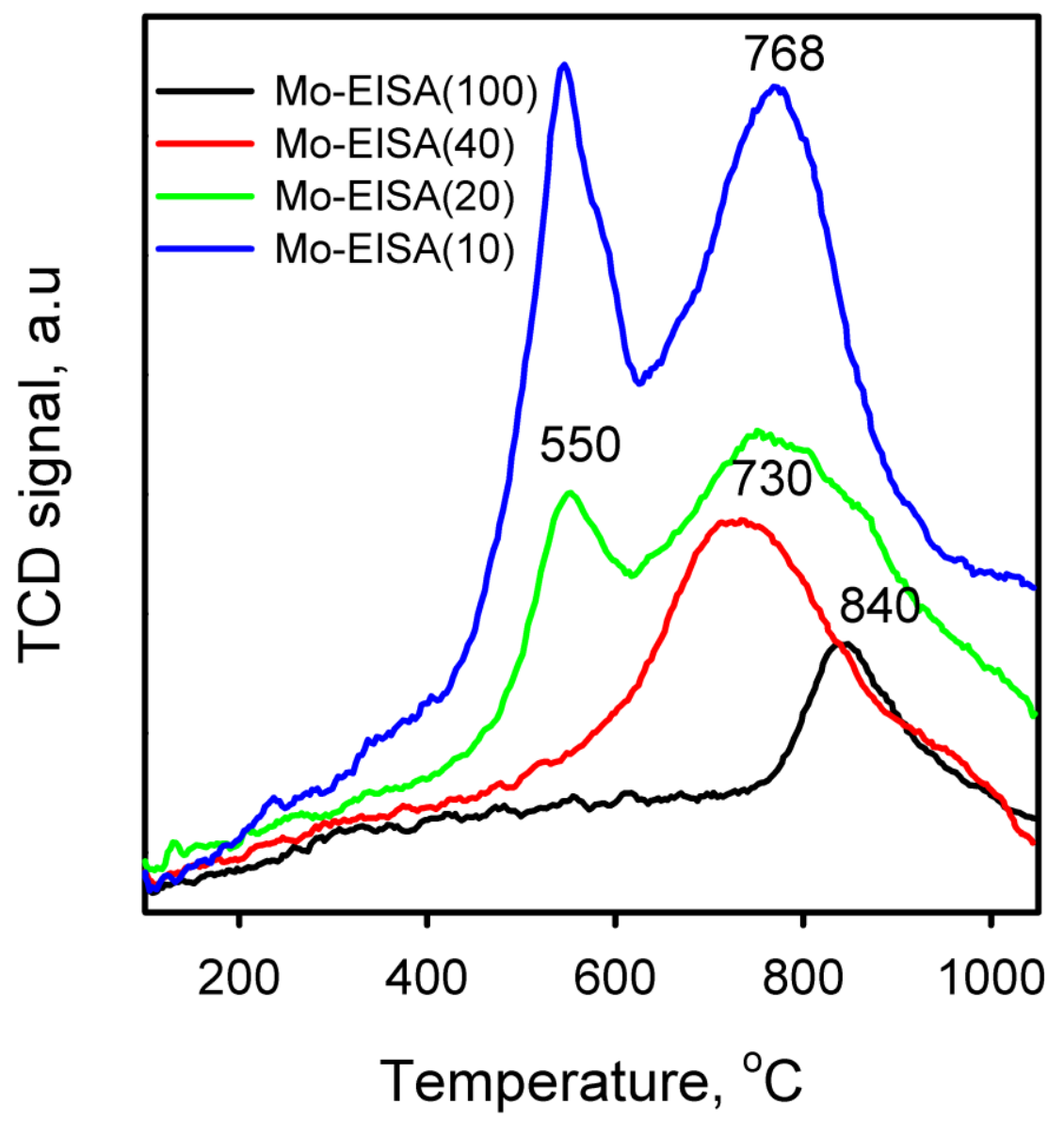

Figure 6. Temperature programmed reduction $\left(\mathrm{H}_{2}-\mathrm{TPR}\right)$ profiles of Mo-EISA (Si/Mo) samples. 


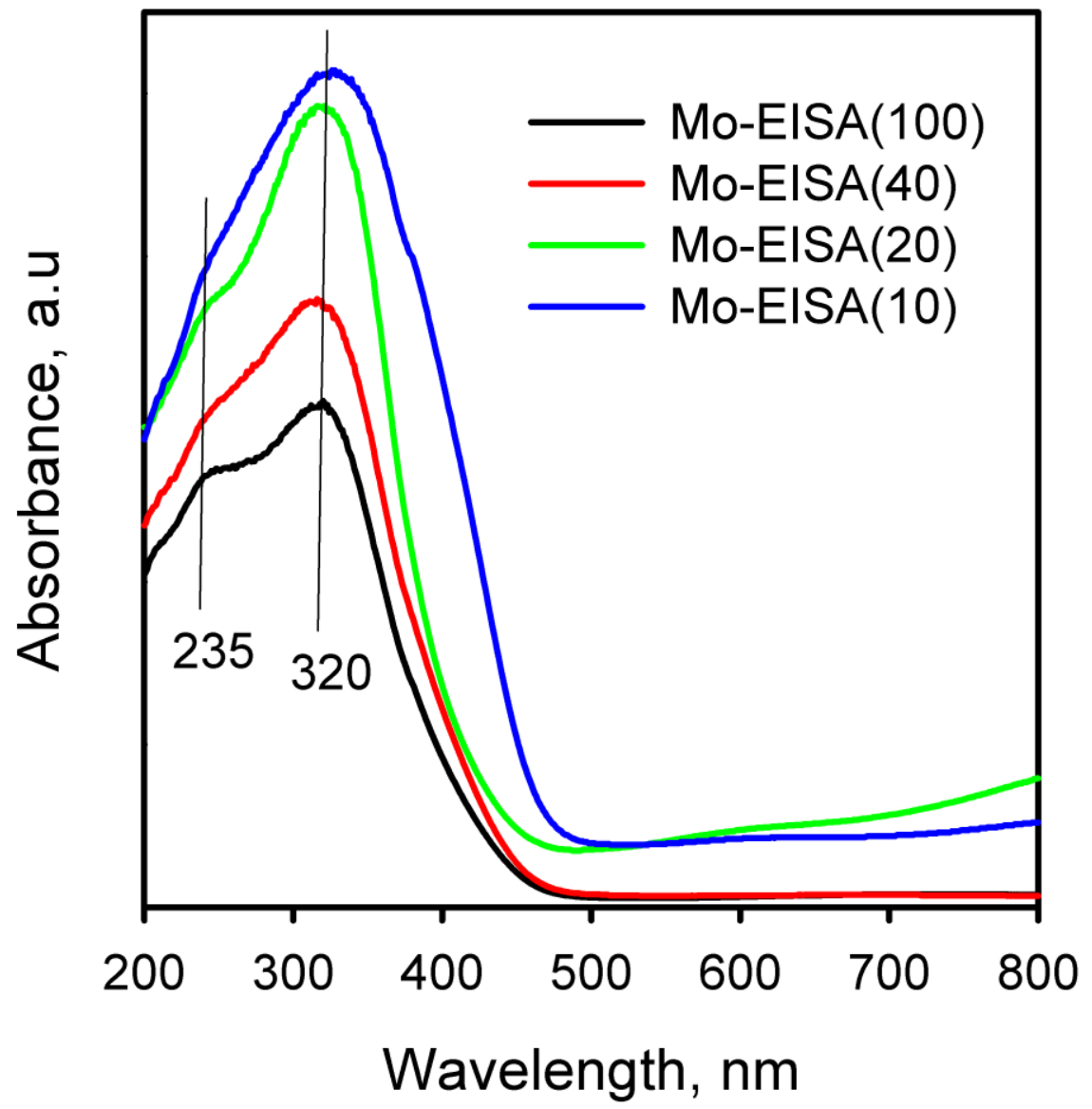

Figure 7. Diffuse reflectance UV-Vis spectra of Mo-EISA(Si/Mo) samples. 


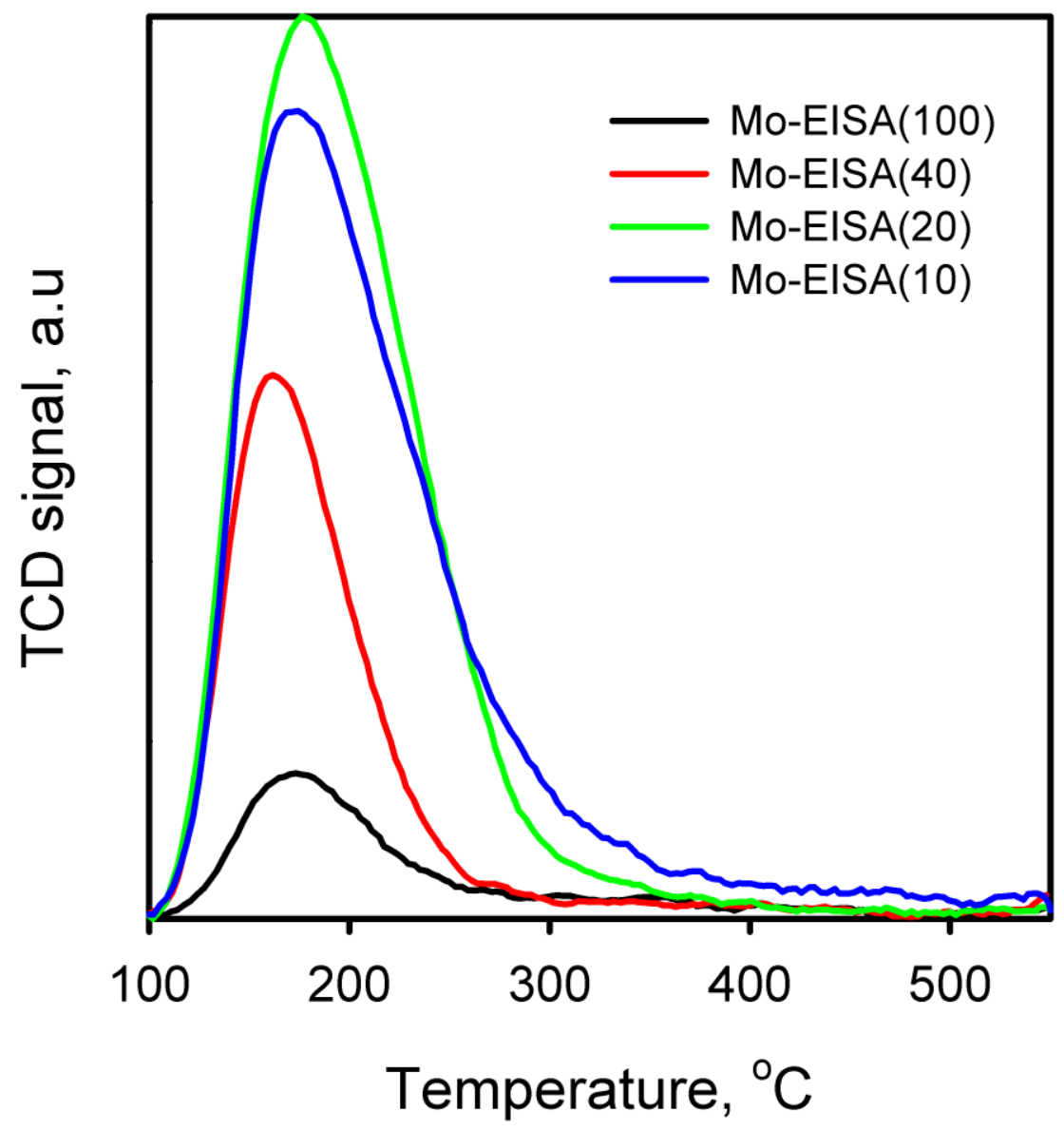

Figure 8. Temperature programmed desorption of ammonia $\left(\mathrm{NH}_{3}-\mathrm{TPD}\right)$ from Mo-EISA(Si/Mo) samples. 

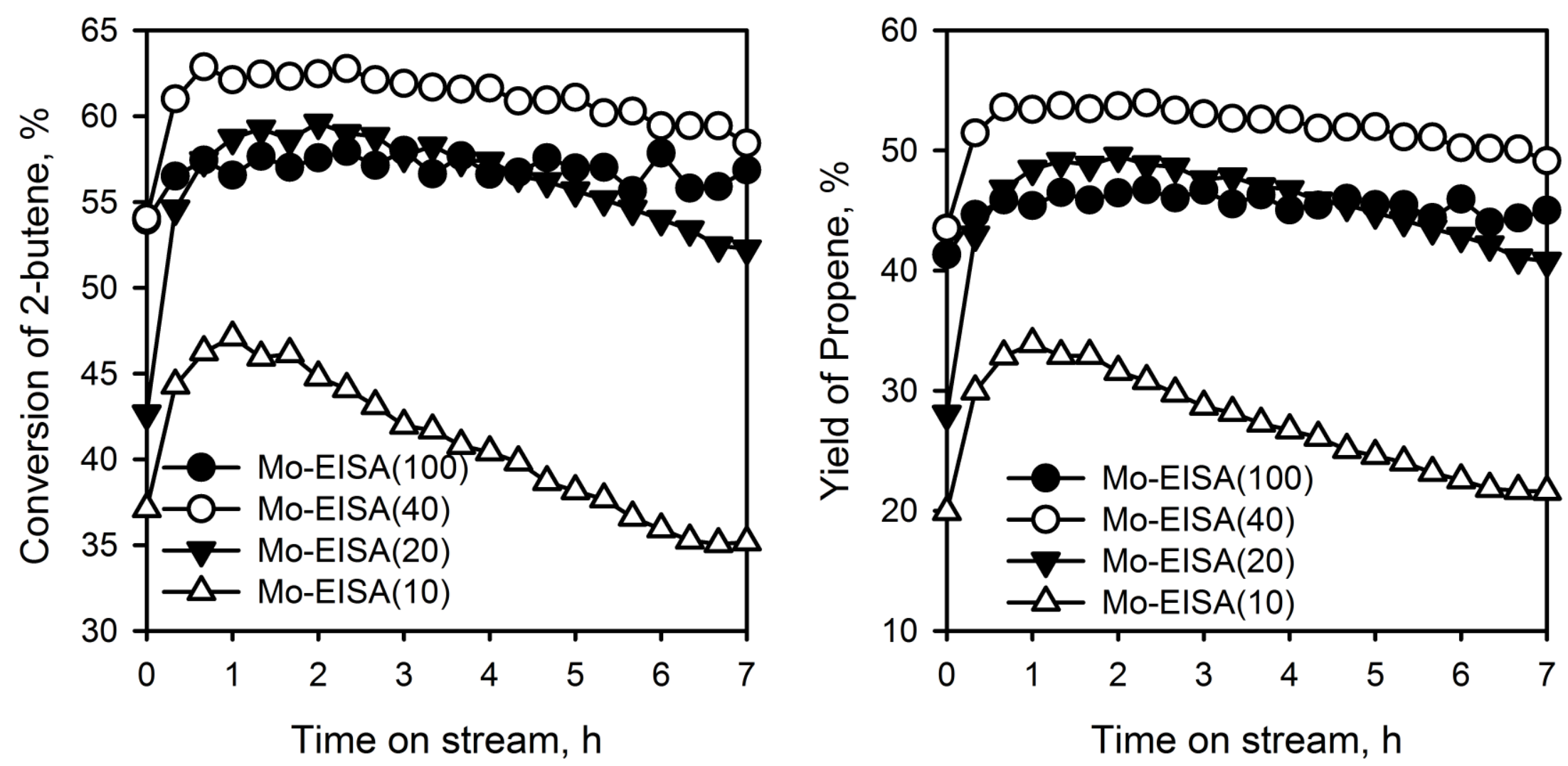

Figure 9. Metathesis activity of Mo-EISA(Si/Mo) catalysts for 2-butene conversion (left) and propene yield (right). 


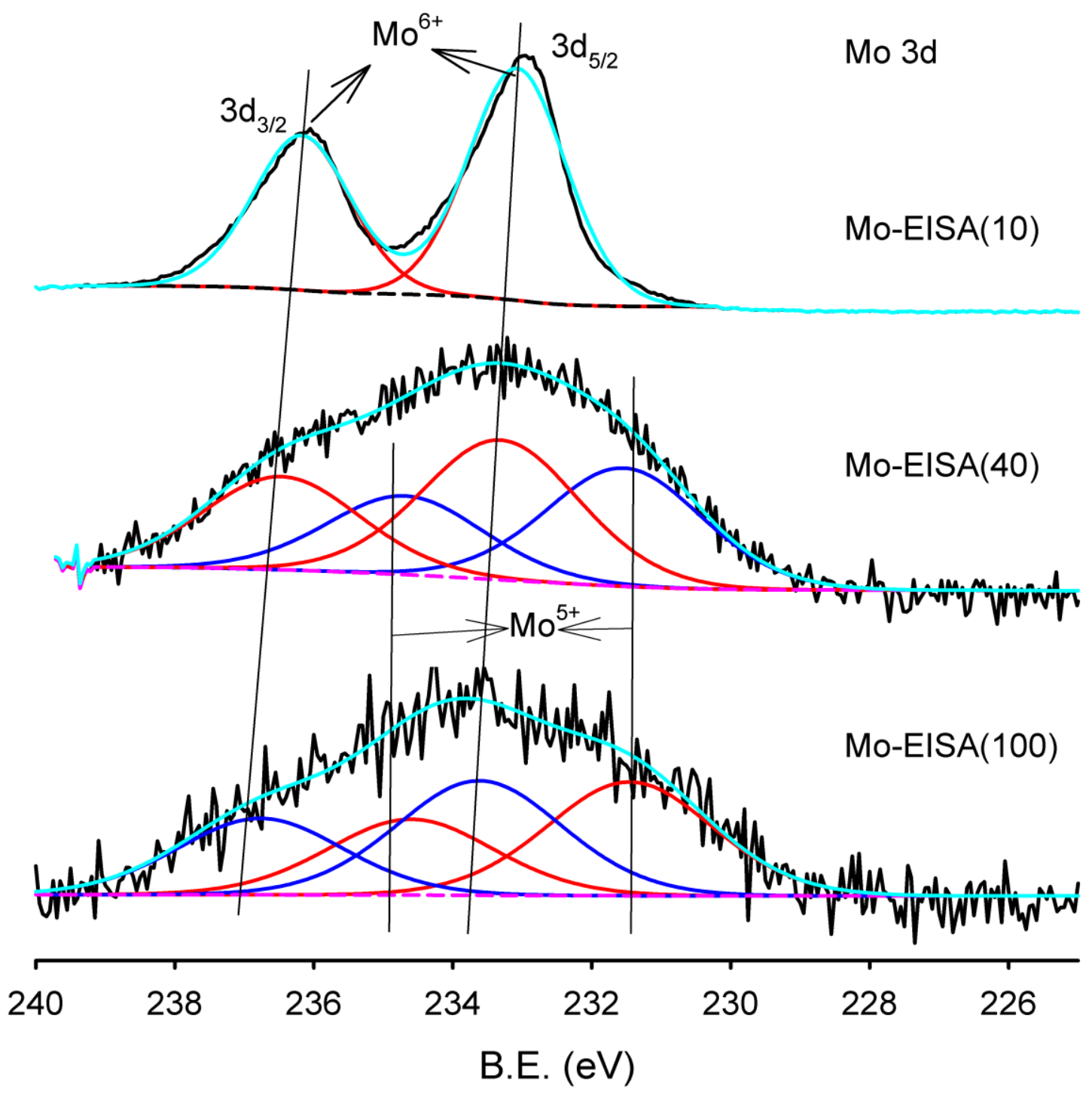

Figure 10. XPS spectra of Mo-EISA samples in Mo3d binding energy region. 

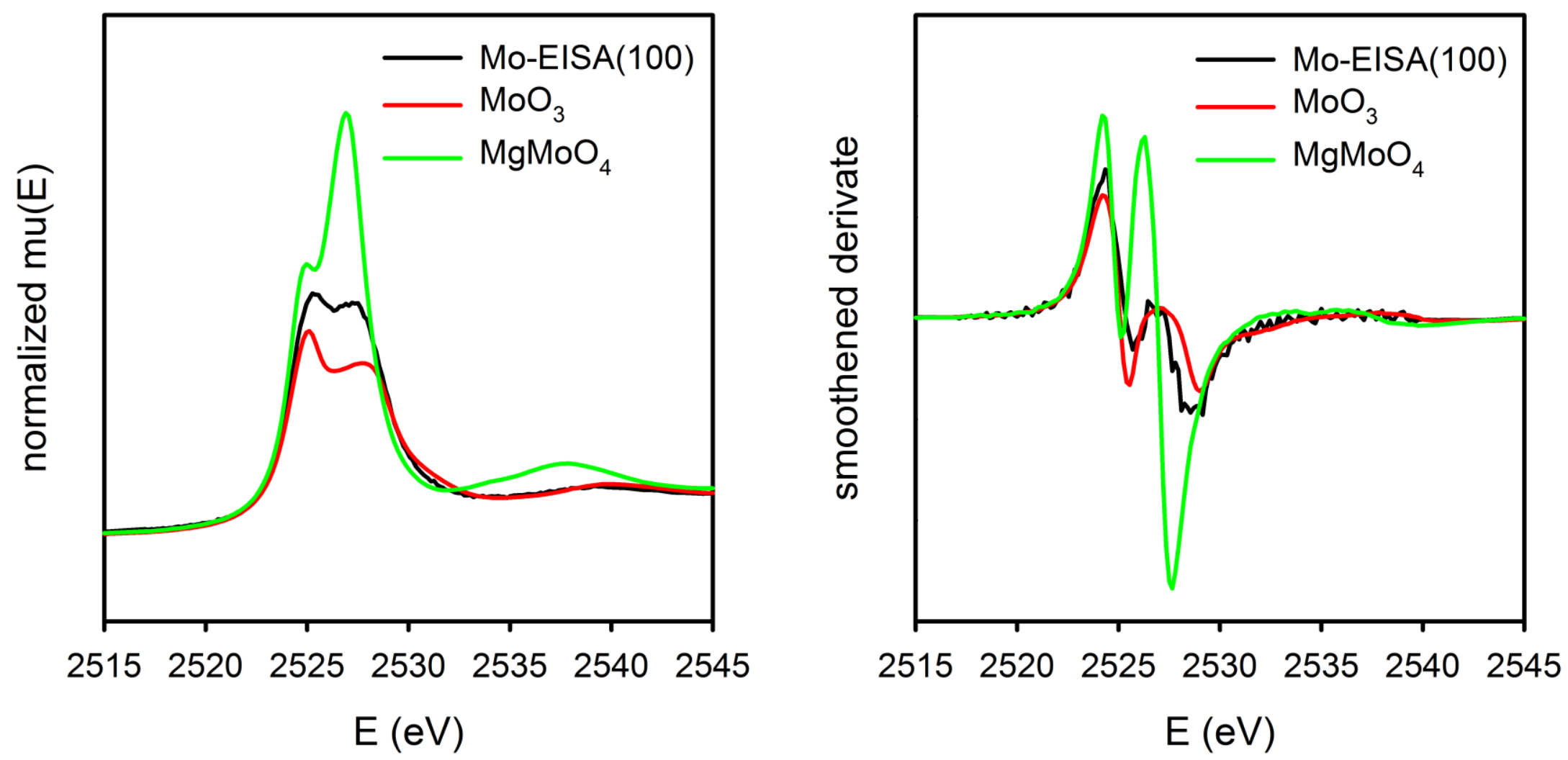

Figure 11. Normalized and the second derivative of Mo L3-edge XANES spectra of Mo-EISA(100) sample compared to $\mathrm{MoO}_{3}$ and $\mathrm{MgMoO}_{4}$ references. 


\section{Graphical Abstract}

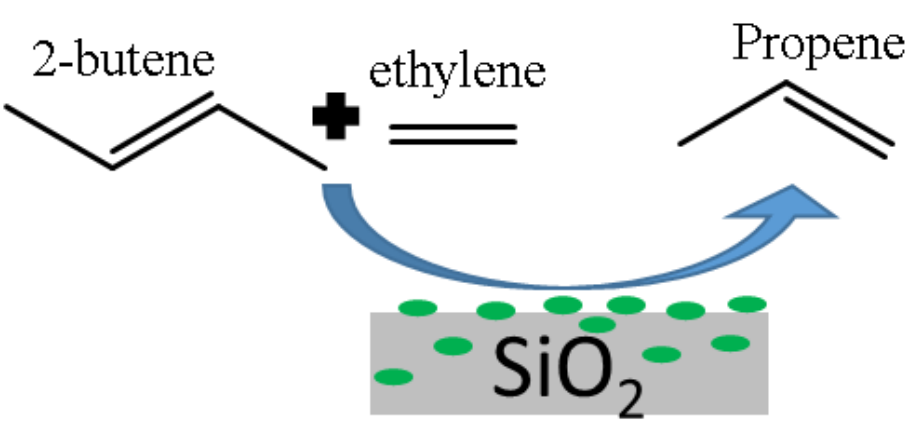

- Surface or incorporated $\mathrm{MoO}_{\mathrm{x}}$

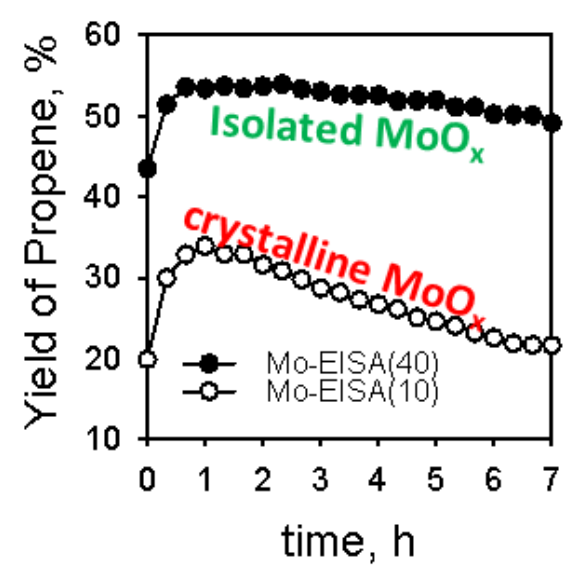

